\title{
Investimentos, arbitragem internacional e o Brasil
}

\author{
Diogo Henrique Tomaz Afonso Alves ${ }^{1}$
}

\section{Resumo}

Este artigo tem por finalidade discorrer brevemente acerca do fenômeno da arbitragem internacional, oferecendo um panorama histórico e político. Desse modo, inicia-se com a determinação dos conceitos usados e a evolução do tema. Em tópicos distintos, procura-se não só caracterizar o regime de investimentos internacionais, mas também seus marcos regulatórios e o papel da arbitragem nesse campo. A visão crítica e analítica da literatura contempla diversos autores nacionais, portanto, há uma inserção do Brasil em todos os assuntos aqui discorridos. A importância da arbitragem encontra-se por ser um fenômeno da modernidade e configura-se forma alternativa de solução de controvérsias, muito usada no Direito Internacional. Uma das áreas que a capacidade de regulação internacional se apresenta com maior profundidade é o das relações econômicas; no que tange aos investimentos internacionais, sobretudo no sentido da imposição de alguns limites importantes à ação dos Estados, o que ocorre tanto mediante as instituições de Bretton Woods - o Banco Mundial e o Fundo Monetário Internacional - quanto no sistema da Organização Mundial do Comércio, ou ainda em blocos econômicos.

Palavras-chave: Arbitragem. Investimentos estrangeiros. Direito Internacional.

\section{Introdução}

A arbitragem é um fenômeno da modernidade, porém é algo que já estava presente no Direito Romano. ${ }^{2}$ Configura-se forma alternativa de solução de controvérsias muito usada no Direito Internacional. No pós-guerra, esse processo ex-

\footnotetext{
1 Analista de política internacional da Embaixada Real da Arábia Saudita no Brasil, Mestre em Direito das Relações Internacionais pelo UniCEUB - Centro Universitário de Brasília.

2 "A arbitragem teve início no Direito Romano e ocorria na fase do apud iudicem, na qual o juiz era livremente escolhido pelas partes, conhecendo e decidindo a controvérsia.
} 
trapola o direito doméstico, saindo dos Estados, para adentrar, em definitivo, como instrumento do Direito Internacional Público e Privado.

Nota-se que a solução de controvérsias pela via da arbitragem não se aplica a pequenas nem a grandes causas, muito menos viria a ser uma terceirização da justiça, uma vez que ela é tutelada pelo ordenamento jurídico do Estado e, posteriormente, imposta sua execução pelas instâncias do judiciário. Nesse sentido, um dos principais desafios do Direito Internacional na atualidade é a criação e a consolidação de sistemas normativos internacionais capazes de incrementar a segurança jurídica internacional, mediante a qual os fluxos econômicos internacionais seriam facilitados pela redução de riscos políticos e custos transacionais. ${ }^{3}$

Um dos campos em que a capacidade de regulação internacional se apresenta com maior profundidade é o das relações econômicas, sobretudo no sentido da imposição de alguns limites importantes à ação dos Estados, o que ocorre tanto mediante as instituições de Bretton Woods - o Banco Mundial e o Fundo Monetário Internacional - quanto no sistema da Organização Mundial do Comércio. Em muitos casos, é possível identificar claramente obrigações imputadas aos Estados e que, pelo menos em alguns casos, estão sujeitas às decisões de terceiros, normalmente, órgãos técnicos ou de solução de controvérsias. ${ }^{4}$ Não obstante, embora o investimento estrangeiro, sobretudo na sua

Porém, o poder do julgador nessa fase derivava do pretor e não das partes”. MUJALLI, Walter Brasil. A nova lei de arbitragem. Leme: Editora de Direito, 1997. p. 40.

3 A globalização econômica trouxe novas formas de proteção de investimentos. Levou também à intensificação do uso de alguns instrumentos tradicionais, como a arbitragem - já na década de 1960, as empresas afetadas pela nacionalização de poços de petróleo no Oriente Médio se valeram de cláusulas arbitrais previstas em seus contratos de concessão. Logo, para não depender do Judiciário do país em que está investindo - que pode ter problemas de eficiência e parcialidade - a empresa pode incluir em seu contrato com aquele Estado uma disposição estabelecendo que eventuais controvérsias deverão ser resolvidas por meio de arbitragem.

4 A exemplo disso estaria o sistema de solução de controvérsias da OMC. Para mais, ver: AMARAL JÚNIOR, Alberto. A solução de controvérsias na OMC. Atlas: São Paulo, 2008. 
modalidade direta, tenha grande complexidade e permeie os sistemas regulatórios internacionais mencionados, ele não está submetido a um regime multilateral específico para sua promoção e proteção.

A Convenção de Washington de 1965, que criou o Centro Internacional para Resolução de Disputas Relativas a Investimentos, ligado ao Banco Mundial, assegura aos investidores de um país contratante que eventuais litígios, envolvendo outro Estado signatário, serão resolvidos por arbitragem. A sentença proferida no âmbito do ICSID obriga as partes - o Estado contratante deve assegurar a sua execução como se fosse um julgamento definitivo de seus tribunais. ${ }^{5}$

\section{Evolução recente do tema}

No que tange à atualidade do tema em questão, cumpre destacar a densa ${ }^{6}$ procura pela forma alternativa de solução de controvérsia no cenário internacional, paralelamente, ao desenvolvimento da arbitragem no plano doméstico e no bojo dos blocos econômicos. Os setores que mais têm buscado a arbitragem estão vinculados ao financiamento internacional com mecanismos próprios do aparato de investimentos. Nesse sentido, está a Convenção de Washington de 1965, que disciplina objetivamente a matéria de investimentos internacionais, a não ser em seu art. 54, que assevera a necessidade de que os países destinatários

5 Esse seria o maior óbice à aceitação do governo brasileiro à referida convenção. A Convenção estabelece que as sentenças arbitrais estrangeiras sejam obrigatórias para os Estados signatários, os quais se comprometem a executá-la segundo seus procedimentos previstos em âmbito interno, respeitando-se as demais condições estabelecidas pela Convenção (artigo III). Para obter o reconhecimento e a execução, a parte demandante deve fornecer os originais ou cópias autenticadas da sentença e da convenção arbitrais (artigo IV).

6 A Arbitragem é um método que foi adotado por diversos países, conquistando seu espaço cada dia mais e provando ser um meio extremamente eficaz. Estatísticas demonstram que, nos tempos atuais, em média de $80 \%$ a $90 \%$, dos litígios têm sido resolvidos por meios das técnicas de mediação, conciliação e arbitragem, principalmente nos países de primeiro mundo. 
de investimentos internacionais venham a aderir à arbitragem prevista no próprio texto do tratado.?

Surge, nesse ínterim um dos maiores óbices à concretude de um sistema normativo que garanta maior segurança ao investidor estrangeiro. Afinal, a eficácia de um sistema de arbitragem é avaliada pela possibilidade de executar a sentença arbitral contra a parte condenada. ${ }^{8}$ Concebida como modo alternativo à solução de litígios através da justiça estatal, a arbitragem propugna pela execução voluntária do laudo pelas partes; na ausência do cumprimento espontâneo, entretanto, será necessário fazer uso dessa mesma justiça estatal para obter a execução forçada da sentença. Nesse sentido, é importante que o sistema preveja mecanismos efetivos para viabilizar a execução. Essa tarefa é especialmente difícil quando se trata de um laudo arbitral condenando um Estado estrangeiro.

O reconhecimento e a execução de sentenças arbitrais estrangeiras foi inicialmente regido em nível internacional por convenções bilaterais, as quais estão dispostas no sitio eletrônico do ICSID, Banco Mundial. Rumo ao desenvolvimento do assunto, o tratamento multilateral inicia-se com o Protocolo de Genebra de

7 Há quem veja nisso uma forma de coagir Estados não hegemônicos e alvo de investimentos internacionais à obediência de regras arbitrais, não propriamente negociadas, mas impostas unilateralmente.

8 O juiz interno não poderia questionar uma decisão cuja força obrigatória decorre do direito internacional; a violação desse direito acarreta consequências para o Estado na esfera da responsabilidade internacional. Para mais, ver: ANDRADE, Isabela P. A execução de sentenças arbitrais contra estados estrangeiros segundo a Convenção de Nova York de 1958 e a Convenção de Washington DE 1965. Revista Brasileira de Direito Internacional, Curitiba, v. 2, n. 2, jul./dez. 2005.

8 Em dezembro de 1929, o governo brasileiro enviou ao Parlamento o Protocolo de Genebra assinado em 24.09.1923 no âmbito da ONU, que viria a ser a primeira convenção relativa à arbitragem ratificada pelo Brasil. Contudo, esse protocolo só foi ratificado pelo Brasil em 05.02.1932, com a ressalva de que se aplicaria o Protocolo apenas para assuntos comerciais. Objetivando a adequação do Brasil à prática da arbitragem comercial internacional, comum em outros países, grande parte da doutrina nacional já defendia a equiparação da cláusula compromissória ao compromisso no plano internacional, com base no Protocolo de Genebra, já que, internamente, somente o compromisso ensejava a instauração do juízo arbitral. Tendo em vistas as dificuldades enfrentadas para o reconhecimento das sentenças arbitrais, foi necessário aditar o Protocolo. Sendo assim, o Protocolo de 1923 foi aditado pela Convenção sobre a execução de laudos arbitrais estrangeiros, que foi assinada em 
1923 e a Convenção de Genebra de 1927. ${ }^{9}$ O interesse prático por esses instrumentos diminuiu sobremaneira após o advento da Convenção de Nova York de 1958, cujas disposições representaram um grande avanço em relação aos acordos de Genebra, em especial no tocante à eliminação do "duplo exequatur" e atribuição do ônus da prova à parte que impugna o reconhecimento ou execução da sentença. Dessa forma, a Convenção de Nova York constitui o principal tratado multilateral sobre o reconhecimento e execução de sentenças estrangeiras, que, desde então, mereceu ser ratificada por mais de 140 países, de modo que se tornou "universalmente" aceita. ${ }^{10}$

A Convenção de Nova York surgiu na fase da reconstrução da Europa, após a Segunda Guerra Mundial, e no início da Guerra Fria. Na época, ante os auspícios de paz universal e a garantia dos direitos humanos, que inspiraram a criação da Organização das Nações Unidas, encontravam-se obstáculos sérios nas relações entre os países de formação, cultura e ideologia diferentes, em relação aos quais era preciso intensificar o comércio, criando, assim, interesses comuns.

Em pouco mais de 50 anos, a convenção valorizou a arbitragem, dando-lhe dimensão internacional e facilitando a circulação das decisões arbitrais no mundo inteiro. Constitui-se, pois, um importante instrumento de solução dos litígios comerciais e, consequentemente, de facilitador do comércio internacional. ${ }^{11}$

Genebra no dia 26 de Setembro de 1927. A convenção estabeleceu que um laudo arbitral poderia ser reconhecido no território de qualquer estado membro, se algumas condições fossem satisfeitas.

${ }^{10}$ Ideia explanada por: COSTA, Larissa. Arbitragem internacional e investimentos. Ed. Lawbook: Pirassununga, 2007. p. 5.

${ }^{11}$ Sombra Saraiva, em sua obra História das Relações Internacionais, assevera que por conta da divisão ideológica do mundo durante a guerra fria, as relações comerciais poderiam mitigar as divergências e criar interdependências econômicas, que, no futuro, permitiram a globalização, conforme se observa durante o período da Détente. As relações comerciais entre o Ocidente e os países comunistas constituíram, assim, as armas da paz. Em um clima de desconfiança, entendia-se que os eventuais conflitos comerciais não podiam estar submetidos à Justiça de um dos países interessados. Para mais, ver: SARAIVA, José Flávio Sombra. História das Relações Internacionais Contemporâneas. 2. ed. Saraiva: São Paulo, 2007. v. 1. 
No advento da globalização, em meio às trocas comerciais que se multiplicavam na década de 1970 e 1980, observa-se maior interconexão entre empresas e Estados do globo. A importância crescente dos países emergentes, iniciada com os tigres asiáticos, e a busca por novos mercados consumidores e produtores, vem oferecendo novas dimensões ao comércio mundial. Ao se intensificar, exige facilitações, que a convenção veio propor, em virtude da institucionalização da arbitragem internacional, nas quais se observa alguma analogia com as facilidades criadas, no tocante ao turismo, pelo cartão de crédito internacional ou nas relações comerciais entre empresas, com as cartas de crédito (catalisadores econômicos e jurídicos dos efeitos construtivos da globalização).

A Convenção de Nova York abriu novos caminhos para que os litígios internacionais pudessem ter soluções rápidas e eficazes, pois logrou proibir qualquer discriminação entre decisões nacionais e estrangeiras, ${ }^{12}$ o que pôde diminuir a burocracia na homologação das sentenças arbitrais quanto ao exequatur em um país diferente daquele em que foram proferidas, a convenção equipara a decisão arbitral à sentença judicial. ${ }^{13}$ Outro ponto que também gera muita polêmica, porém contribuiu para torná-la ímpar, foi o estabelecimento de regras às cláusulas compromissórias, incluídas em qualquer documento, que obrigam as partes a se submeterem à arbitragem, independente da assinatura de termos de compromisso com esse intuito. Isso significa que as partes se sujeitariam irrevogavelmente à arbitragem para dirimir os eventuais conflitos futuros antes mesmos que eles pudessem vir a surgir.

\footnotetext{
${ }^{12}$ Logo no Art. I há clara explanação do que viria a ser sentença estrangeira e internacional, assim como nacional, vetando a discriminação entre elas.

${ }^{13}$ Também limitou os casos de impugnação da homologação das sentenças arbitrais estrangeiras, presumindo a validade das mesmas e fazendo pesar sobre o impugnante o encargo de provar as eventuais ilegalidades. A Convenção de Nova York determinou, ainda, que na homologação de sentenças estrangeiras, não cabia ao tribunal examinar o mérito das decisões arbitrais, mas tão-somente a regularidade do processo. Finalmente, considerou que somente havendo violação da ordem pública é que as sentenças arbitrais estrangeiras não deveriam ser homologadas.
} 


\section{0 contexto internacional de investimentos e arbitragem para o Brasil}

Nota-se que, nos últimos anos, o Brasil deixou de ser um país exclusivamente recebedor de investimentos para tornar-se também um investidor, com empresas ganhando porte de multinacionais como a Petrobrás, a Vale, a Gerdau e a Votorantin, entre outras. Desde 2000, os investimentos diretos do país no exterior totalizam US\$ 54,5 bilhões líquidos, segundo dados do Banco Central. ${ }^{14} \mathrm{~A}$ mudança de posição leva a considerar novamente a assinatura da Convenção de Washington ou dos acordos bilaterais de proteção de investimentos, uma vez que o Brasil ocupa hoje o $14^{\circ}$ lugar no ranking dos países com maior estoque de investimento direto no exterior, cerca de US\$ 220 bilhões em 2006. ${ }^{15}$ Acontecimentos recentes, envolvendo empresas públicas e privadas brasileiras na Bolívia e no Equador, chamam a atenção para um potencial obstáculo à expansão das empresas brasileiras no exterior, no que tange à proteção de investimentos. ${ }^{16}$ Essa mudança de posição traz à tona a discussão, porém de forma inversa, quanto às proteções dos investimentos externos de empresas nacionais.

INVESTIMENTOS BRASILEIROS DIRETOS LÍQUIDOS NO EXTERIOR 1968 - 2004

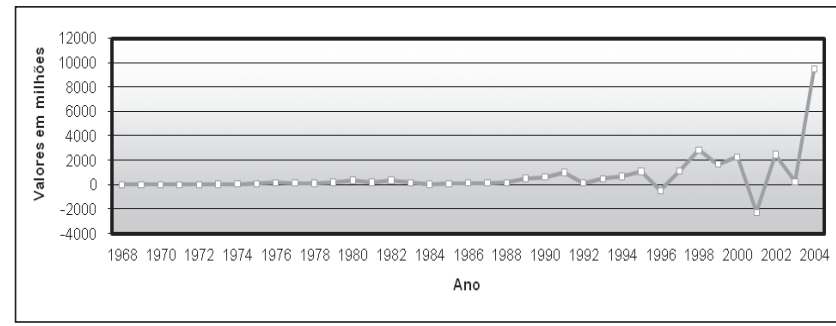

Fonte: Bacen - BEPEC 2004

${ }^{14}$ Dados sitio eletrônico do Banco Central do Brasil, disponível em: www.bcb.gov.br.

${ }^{15}$ Pesquisas da Sobeet, CNI e KPMG apontam que os investimentos dessas multinacionais oscilaram de US\$ 28,6 bilhões em 2006 e US\$ 18 bilhões em 2007 para US\$20,5 bilhões em 2008. Disponível em: <http://www.sobeet.org.br/boletim.php>.

${ }^{16} \mathrm{O}$ Brasil não dispõe de nenhum acordo de proteção e garantia de investimento com os países da América do Sul, onde os riscos para as empresas multinacionais brasileiras estão aumentando rapidamente. Quando a Bolívia ocupou militarmente duas refinarias da Petrobrás, o governo brasileiro não recorreu ao acordo de garantia de investimentos entre a Holanda e a Bolívia, recurso cabível, já que a compra foi feita por subsidiária da Petrobrás sediada nos Países Baixos. Não se sabe, porém, se no momento do acordo tal prerrogativa foi proposital pelo governo brasileiro, mais precisamente, pela Petrobrás. 
Por meio da análise do gráfico, pode-se observar um crescimento expressivo em relação a 2003, quando foram registrados apenas 249 milhões de dólares em investimentos brasileiros diretos no exterior. Do total de 2004, 6,6 bilhões foram referentes a aumentos de participações, dos quais quase cinco bilhões foram resultado da troca de ativos entre a Ambev e a Interbrew: a operação representou US\$ 4,9 bilhões em investimento estrangeiro direto na forma de participações e, como os antigos controladores da Ambev também adquiriram participação no capital da Interbrew, ocorreu investimento brasileiro direto no exterior em igual montante. Devido a essa operação, os investimentos do terceiro trimestre de 2004 corresponderam a quase $85 \%$ do total registrado no ano. ${ }^{17}$

Na perspectiva do tempo, a arbitragem internacional é uma instituição muito antiga. A arbitragem como jurisdição privada antecedeu a jurisdição estatal, sendo que a solução de controvérsias, por meio da arbitragem, aconteceu de diversas formas e esteve presente na sociedade humana desde os primórdios. No Brasil, a arbitragem é reconhecida desde os tempos da colonização portuguesa, expressa nas Ordenações Filipinas e Manuelinas; ${ }^{18}$ tendo inclusive sido obrigatória até 1866, para algumas matérias indicadas no Código Comercial de 1850. O compromisso, como modo de extinção das obrigações, foi disciplinado no Código Civil de 1916. Já o juízo arbitral foi previsto, de modo uniforme para todo o Brasil, no Código de Processo Civil de 1939 e, posteriormente, sem grandes alterações, no de 1973. Em 1996, com o advento da Lei 9.307/96, a Lei de Arbitragem, a matéria passou a ter uma legislação específica, tendo sido revogadas normas do Código Civil e do Código de Processo Civil. Com a edição do Novo Código Civil, seus art. 851, 852 e 853 passam a tratar do compromisso arbitral para resolver litígios, remetendo à disciplina legislação específica. ${ }^{19} \mathrm{~A}$ globalização dos negócios comerciais tem tornado cada vez mais recorrente a adoção do instituto da arbitragem

${ }^{17}$ BANCO CENTRAL DO BRASIL. Capitais brasileiros no exterior - Data-base 2001, 2002, 2003 e 2004. BACEN, 2004. Disponível em: <http://www.bcb.gov.br>. Acesso em: 18 maio, 2009.

${ }^{18}$ SILVA, José A. da. Arbitragem dos contratos comerciais no Brasil. Belo Horizonte: Del Rey, 1997. p. 56

${ }^{19}$ CARMONA Carlos Alberto. Arbitragem e processo: um comentário à Lei. 9.307/96. Malheiros Editores: São Paulo, 1998. p. 45. 
nos contratos internacionais, conforme já explanado. Atualmente, a comunidade internacional de negócios se utiliza em $80 \%$ dos casos comerciais da arbitragem como método de solução de conflitos. Com maior destaque para o transporte marítimo, a indústria do petróleo e os contratos internacionais de grandes complexos comerciais, casos em que chegam a empregar a arbitragem em, aproximadamente, $100 \%$ dos litígios. ${ }^{20}$

No Brasil, a Lei no 9.307, de 1996, buscou os principais tópicos da Convenção de Nova York para redação de seu texto normativo. ${ }^{21}$ É uma lei muito moderna e faz referência à jurisprudência como um todo, que vinha suscitando várias discussões durante a década de 1990. Entretanto, há um problema de constitucionalidade na lei, ${ }^{22}$ o que a levou a ficar sob judice de 1996 a 2002, quando o Brasil aderiu à convenção de Nova York. Chegou-se a afirmar que, anteriormente, tinha havido uma espécie de ratificação tácita pela legislação nacional brasileira do referido tratado, constituindo uma espécie de costume. Os tribunais brasileiros têm aplicado a Convenção de Nova York, e o Superior Tribunal de Justiça salientou, em vários acórdãos, a importância crescente da arbitragem no comércio internacional,

${ }^{20}$ CARMONA Carlos Alberto. Arbitragem e processo: um comentário à Lei. 9.307/96. São Paulo: Malheiros, 1998. p. 45.

${ }^{21}$ Cumpre salientar que em 23 de setembro de 1996 o processo de arbitragem comercial no Brasil recebeu um novo tratamento jurídico com a Lei de Arbitragem 9.307, tornando-se compatível com o dinamismo do comércio e em harmonia com a arbitragem internacional. Dentre os mecanismos alternativos de solução de controvérsias como a mediação e a conciliação, o de maior eficácia e aceitação é a arbitragem. A Lei da Arbitragem baseouse em convenções internacionais como a de Nova York e a Lei-modelo da UNCITRAL, e incorporou à letra da lei, princípios da ordem internacional com o intuito de alcançar uma maior integração global, e de adequar-se a padrões externos, como se nota pela redação dos artigos 38 e 39 da Lei 9.307, os quais praticamente se igualam ao disposto nos artigos IV e V da Convenção de Nova York. Para mais, ver MUNIZ, Tânia L. Arbitragem no Brasil e a Lei 9.307/96. Curitiba: Juruá, 2000.

22 A lei de Arbitragem, como ficou conhecida a Lei 9.3307 de 1996, chocava-se com o inciso 35 do art.5 da Constituição Federal, quanto à apreciação do judiciário nacional de sentença proferida por outra autoridade, quer seja no exterior ou não. Ficou, assim, sob apreciação do Supremo Tribunal Federal por um longo período, em que se alegava a privatização da justiça. Entretanto, conforme salienta Jorge Fontoura, a arbitragem não atenta contra a indeclanibilidade do poder judiciário, ou seja, a tutela do Estado. O arbitro é juiz de fato e de direito, aplicando o direito que as partes recomendam. 
admitindo a prova da existência de cláusula compromissória, o que veio a permitir o aprimoramento da arbitragem no país. ${ }^{23}$

A Emenda Constitucional no 45/2004 trouxe uma grande mudança no que concerne à homologação de sentenças e laudos arbitrais estrangeiros, pois alterou o disposto no art. 105 da Constituição da República Federativa do Brasil, acrescentando a alínea "i" ao mencionado artigo; transferindo assim, a competência exclusiva para homologar sentenças estrangeiras do Supremo Tribunal Federal para o Superior Tribunal de Justiça. Atualmente, para que as decisões estrangeiras tenham validade e produzam efeitos dentro do território nacional, é necessária a homologação da sentença pelo STJ. ${ }^{24} \mathrm{O}$ trâmite legal desse procedimento homologatório deveria estar previsto no Regimento Interno do STJ. Porém, como a alteração é recente, a previsão legal está na Resolução 09, editada pelo STJ para regular essa matéria e outras, como a concessão de cartas rogatórias e expedição de exequatur, também introduzidas pela EC 45/2004. ${ }^{25}$ A homologação pode ser parcial em casos que o STJ entender que só uma parte da decisão está de acordo com as regras homologatórias. Pode ainda, ser admitida a tutela antecipada em casos de urgência. O juízo homologatório é apenas de delibação, não se adentrando no mérito da questão, devendo ser observado os seguintes requisitos: laudo arbitral ou sentença proferida por autoridade competente, partes citadas ou verificada legalmente à revelia e trânsito em julgado da decisão; a decisão deve estar autenticada por cônsul brasileiro e traduzida por tradutor oficial ou juramentado. O primeiro laudo estrangeiro homologado pelo STJ foi o da sentença estrangeira contestada 856-EX (2005/0031430-2) no caso L'Aiglon S/A, empresa suíça, contra Têxtil União S/A, empresa brasileira com sede no Ceará. A empresa brasileira foi condenada a pagar o montante de $\mathrm{R} \$ 900.000,00$ à empresa suíça, referente ao descumprimento parcial do contrato de compra e venda de algodão cru. $\mathrm{O}$ laudo arbitral em questão foi proferido pela Liverpool Cotton Association, com sede

${ }^{23}$ Ideia extraída do texto de Melina Girardi Fachin. Para mais, ver: FACHIN, M. Problemas e perspectivas da participação de Estados e entidades públicas enquanto partes no juízo arbitral. Revista Brasileira de Direito Internacional, Curitiba, v. 2, n. 2, jul./dez. 2005. p. 11-19.

${ }^{24}$ CALLUF FILHO, Emir. Arbitragem internacional: o local da arbitragem. Juruá: Curitiba, 2006. p. 124.

${ }^{25}$ CALLUF FILHO, Emir. Arbitragem internacional: o local da arbitragem. Juruá: Curitiba, 2006. p. 137. 
no Reino Unido. Na homologação desse laudo arbitral, o STJ utilizou pela primeira vez a Convenção de Nova York para embasar a homologação. ${ }^{26}$

É necessário, ainda, ressaltar que o Brasil assinou 14 acordos bilaterais de garantia de investimentos ${ }^{27}$ para proteger investimentos ao longo da década de 1990, em meio ao cenário de neoliberalismo advindo com o governo PSDB. Ademais, outros 16 acordos já haviam sido assinados; entretanto, o atual governo retirou esses acordos do Congresso Nacional, os quais estavam em processo de ratificação, em função da não aceitação da submissão das disputas sobre investimentos às cortes internacionais de arbitragem, do mecanismo de solução de controvérsias e das regras de indenização por expropriação. ${ }^{28}$ Nota-se, nesse ínterim, uma disputa política e ideológica das bases legislativas, que ante ao processo de globalização favorável ao Brasil e ao otimismo da economia internacional, não sacrificaram as expansões de investimentos no país. Mas, com a recente crise, pode haver algum revés nessa posição, pois a nova perspectiva para as empresas brasileiras é de fragilidade, quando passam de receptoras a credoras internacionais. A internacionalização das empresas brasileiras, sobretudo na América Latina, na África e na Ásia, demanda que se examine esse assunto sob outra perspectiva.

No que se refere aos acordos de proteção e garantia de investimentos, a posição do governo até recentemente poderia ser explicada pelo reduzido número de empresas e pela consequente ausência de investimentos brasileiros significativos no exterior, situação que se inverte nos anos da administração do Partido das Trabalhistas e o otimismo da economia internacional presenciado até 2008. Além disso, o clima de

\footnotetext{
${ }^{26}$ ARAÚJO, Nádia de. Direito internacional privado: teoria e prática brasileira. Rio de Janeiro, Renovar, 2003. p. 173.

${ }^{27}$ A expansão desses acordos levou à formação de uma rede de proteção dos investimentos que se espalha por todo o mundo - há aproximadamente 2.500 TBIs e mais de 170 Estados concluíram ao menos um tratado desse tipo. Nesse aspecto, novamente se nota que outros países em desenvolvimento estão à frente do Brasil.

${ }^{28}$ O País não ratificou o tratado que criou, há 43 anos, o Centro Internacional para Resolução de Conflitos sobre Investimentos entre Estados Nacionais e outros Estados (CIRCI) - ou Centre for Settlement of Invesment Disputes (ICSID) - órgão ligado ao Banco Mundial e criado exclusivamente para resolver qualquer tipo de disputa. O objetivo desce centro mediador é ser uma alternativa eficaz e confiável para resolver conflitos legais entre empresas privadas em estados de diferentes nacionalidades.
} 
neoliberalismo e seu repúdio por partes significativas da sociedade, cujo clímax teria sido o embate sobre a ALCA, poderia também justificar a recusa das ratificações.

\section{Regionalismo e papel da arbitragem}

Explanados tópicos que contemplam o panorama da arbitragem internacional, investimentos no exterior e no Brasil, urge algumas palavras a respeito do regionalismo. A arbitragem é a forma essencial para solucionar litígios em blocos econômicos, porquanto comércio sempre gera conflitos. Além disso, a globalização se caracteriza hoje pelos processos integracionistas, e é nesse sentido que se nota em todos os continentes processos com tal intuito. Cabe destacar que o Mercado Comum do Sul (MERCOSUL) advém do adensamento desta realidade, que tem necessidade de responder aos conflitos de dinamismo e abertura do comércio atual em vistas ao desenvolvimento dos Estados partes.

Assim, surgem alheios ao Estado, mecanismos alternativos de solução de controvérsias, que encontram o seu auge no campo das relações dos sujeitos de Direito Privado, o qual se prima pela autonomia da vontade. ${ }^{29}$ Desses mecanismos, o principal seria a arbitragem. Nos blocos supranacionais, a solução é jurídica, como se observa no Tribunal Europeu das Comunidades Europeias, o que facilita o exequatur, sendo esse processo automático e sem possibilidades de recursos.

Em modelos de integraçào regional intergovernamentais, o processo de solução de controversias é resolvido segundo o Direito Internacional Público, ou seja, da negociação direta parte-se para a mediaçào; por fim, quando não se acha um entendimento, vai-se para a arbitragem. Ao se buscar uma solução no MERCOSUL, depara-se com dois acordos de proteção de investimentos, ambos de 1994. Um deles, o de Buenos Aires, trata de investimentos nos países do bloco, provenientes de outros Estados. O outro é o Protocolo de Colônia, que interessa ao

\footnotetext{
${ }^{29}$ KRAUSS, Merly Lysett. reconocimiento y execucion del laudo arbitral internacional en el MERCOSUR. Revista Brasileira de Direito Internacional, Curitiba, v. 2, n. 2, jul./dez. 2005. p. 76.
} 
empresariado brasileiro, por ser aplicável a investimentos entre os países membros. Ambos conferem aos investidores a possibilidade de adotar a arbitragem como forma de solução de disputas, porém, nenhum deles está em vigor.

Ainda no que concerne ao MERCOSUL, o Grupo de Mercado Comum funciona como um mediador para solucionar controvérsias. De 1991 até1998, houve, apenas 9 arbitragens no âmbito do bloco, pois a diplomacia foi muito atuante nesse período, o que levou os casos a serem resolvidos por meio do diálogo. A saber, Brasil e Argentina mantiveram consultas de alto nível entre seus diplomatas, com o intuito de dirimir possíveis contradições comerciais. O sistema de solução de controversias do MERCOSUL seria uma segurança para quem negocia, mais do que a própria eficácia, estaria a garantia de um órgão permanente. ${ }^{30}$ De acordo com o professor Jorge Fontoura, ${ }^{31}$ o calcanhar de Aquiles na arbitragem intra-blocos econômicos está nas listas de arbitros pelas partes, mesmo com a livre escolha limitada, e por conta de um Tribunal Permanente de Revisão. No TPR do MERCOSUL há opiniões consultivas, de grande valor, além de ser uma segunda instância revisora após a arbitragem formal entre as partes, e os poderes juduciários dos Estados-partes podem solicitar pareceres ao referido tribunal, o que não é obrigatorio, mas meramente exortatório.

\section{Considerações finais}

Conforme destaca o professor Ives Gandra da Silva Martins, ${ }^{32}$ nada pode lesar tão gravemente a imagem do sistema arbitral relativo a investimentos que

\footnotetext{
${ }^{30}$ Sempre resta a opção, clássica no direito internacional, de o governo brasileiro, utilizando o mecanismo da proteção diplomática, agir em defesa da empresa nacional na Corte Internacional de Justiça, em Haia. Mas já ficou demonstrado que as empresas tendem a perder com soluções em que o jurídico é contaminado pelo político.

31 Aulas proferidas pelo professor Jorge Fontoura no curso de Mestrado em Direito das Relações Internacionais, no segundo semestre de 2009, disciplina Solução de Controvérsias Comerciais e Arbitragem Internacional.

32 MARTINS, Ives Gandra da Silva; REZEK, Francisco José de Castro. Atualidades da arbitragem internacional relativa a investimentos. Revista Projuris on-line. Disponível em: <http://www.gandramartins.adv.br/art_detalhes.asp?id=392>. Acesso em 26 jun. 2009.
} 
sua falta de qualidade para bem aplicar o direito e realizar a justiça, naqueles poucos casos em que o requerido é muito mais um Estado exportador de capital do que um receptor de investimentos estrangeiros. Se a arbitragem revelar-se, afinal, uma via de mão única na proteção do investimento estrangeiro, mostrando fraqueza quando se espera que corrija a violação dos direitos do investidor por um Estado economicamente mais forte que o Estado patrial desse investidor, é inevitável que o sistema tome ares de um instrumento variante do neocolonialismo, ${ }^{33}$ e que a maioria dos Estados se sinta tentada a reconsiderar sua participação no sistema. Uma dinâmica e importante parte do direito internacional contemporâneo haveria de sofrer as consequências desse desapontamento, segundo o que assevera Yves Martins. ${ }^{34}$

Acordos internacionais de proteção propiciam a segurança jurídica necessária à criação de um ambiente favorável aos investimentos. A relutância do Brasil em relação a esses acordos se justifica pelo fato de o País ser tradicionalmente um receptor de investimentos. No entanto, nos últimos anos, as empresas brasileiras ampliaram a sua atuação no estrangeiro por verem na internacionalização uma oportunidade e, muitas vezes, uma necessidade.

Hoje, o estoque de investimentos brasileiros no exteior ultrapassa a cifra de US\$ 129 bilhões - três vezes maior do que na década de1990. Para tanto, roga-se que o país mude sua postura, dando maior atenção à proteção de investimentos no exterior por parte das empresas nacionais.

\footnotetext{
${ }^{33}$ MARTINS, Ives Gandra da Silva; REZEK, Francisco José de Castro. Atualidades da arbitragem internacional relativa a investimentos. Revista Projuris on-line. Disponível em: http://www.gandramartins.adv.br/art_detalhes.asp?id=392. Acesso em 26 jun. 2009.

${ }^{34}$ MARTINS, Ives Gandra da Silva; REZEK, Francisco José de Castro. Atualidades da arbitragem internacional relativa a investimentos. Revista Projuris on-line. Disponível em: http://www.gandramartins.adv.br/art_detalhes.asp?id=392. Acesso em 26 jun. 2009.
} 


\section{Investments, the international arbitration and Brazil}

\section{Abstract}

This article aims to briefly discuss on the phenomenon of international arbitration, giving a historical and political landscape. Thus, it begins with the determination of the concepts used and development of the theme. In other separated topics, we not only characterize the system of international investment, and its regulatory framework, as well the role of arbitration in this context. The analytical and critical view of the literature used includes several national authors; therefore, there is an insertion of Brazil in all matters here presented. The importance of arbitration is to be a phenomenon of modernity and it has become an alternative form of settlement disputes, much used in international law. One area that the ability of international regulation is presented in greater depth is on economic relations, in terms of international investments, especially towards the imposition of some important limits to the action of states, which occurs either by the Bretton Woods institutions - the World Bank and International Monetary Fund - as in the World Trade Organization, or even economic blocs.

Keywords: Arbitration. Foreign investment. International law.

\section{Referências}

ACCIOLY, Elizabeth. Solução de controvérsias em blocos econômicos: contributo para o aperfeiçoamento do sistema de solução de controvérsias do MERCOSUL. Almedina: Coimbra, 2004.

AMARAL JÚNIOR, Alberto do. A solução de controvérsias na OMC. Atlas: São Paulo, 2008.

ANDRADE, Isabela P. A execução de sentenças arbitrais contra Estados estrangeiros segundo a Convenção de Nova York de 1958 e a Convenção de Washington de 1965. Revista Brasileira de Direito Internacional, Curitiba, v. 2, n. 2, jul./dez. 2005.

ARAÚJO, Nádia de. Direito internacional privado: teoria e prática brasileira. Rio de Janeiro, Renovar, 2003. 
BANCO CENTRAL DO BRASIL. Capitais brasileiros no exterior - Data-base 2001, 2002, 2003 e 2004. BACEN, 2004. Disponível em: <http://www.bcb.gov.br>. Acesso em: 18 maio 2009.

CALLUF FILHO, Emir. Arbitragem internacional: o local da arbitragem. Juruá: Curitiba, 2006.

CARMONA, Carlos Alberto. Arbitragem e processo: um comentário à Lei. 9.307/96. São Paulo: Malheiros, 1998.

COSTA, Larissa. Arbitragem internacional e investimentos. Pirassununga: Lawbook, 2007.

FACHIN, M. Problemas e perspectivas da participação de Estados e entidades públicas enquanto partes no juízo arbitral. Revista Brasileira de Direito Internacional, Curitiba, v. 2, n. 2, jul./dez.2005.

FONTOURA, Jorge. A imanência jurídica da OMC. Revista de Informação Legislativa, Brasília, ano 39, n. 153, jan./mar. 2002.

KRAUSS, Merly Lysett. Reconocimiento y execucion del laudo arbitral internacional 11 Mercosur. Revista Brasileira de Direito Internacional, Curitiba, v. 2, n. 2, jul./dez. 2005.

MARTINS, Ives Gandra da Silva; REZEK, Francisco José de Castro. Atualidades da arbitragem internacional relativa a investimentos. Revista Projuris on-line. Disponível em: <http://www.gandramartins.adv.br/art_detalhes.asp?id=392>. Acesso em: 26 jun. 2009.

SILVA, José A. da. Arbitragem dos contratos comerciais no Brasil. Belo Horizonte: Del Rey, 1997. 